\title{
The Recollection of Morning Sickness and Their Support System as Documented by Women Post Pregnancy
}

\author{
Hanna Ericson ${ }^{1}$, Malin Sunnergren ${ }^{1}$, Annsofie Adolfsson ${ }^{1,2}$ \\ ${ }^{1}$ Department of Obstetrics and Gynecology, Skaraborg Hospital, Skövde, Sweden \\ ${ }^{2}$ School of Health and Medical Sciences, Örebro University, Örebro, Sweden \\ Email: annsofie.adolfsson@oru.se
}

Received April 22, 2013; revised May 22, 2013; accepted May 30, 2013

Copyright (c) 2013 Hanna Ericson et al. This is an open access article distributed under the Creative Commons Attribution License, which permits unrestricted use, distribution, and reproduction in any medium, provided the original work is properly cited.

\begin{abstract}
Nausea during pregnancy affects about ten percent of all pregnant women. The causes of nausea and vomiting during pregnancy are unclear. The condition can lead to dehydration, electrolyte derangement, impaired organ function and lead to serious health issues or even death if left untreated. The treatment conducted today is symptomatic and is not completely satisfactory. Objective: The purpose of the study was to describe women's experience of morning sickness and their experience of support. Design: Data was collected through a semi-structured questionnaire and analyzed by qualitative content analysis. Participants: Nine women responded to the survey. Results: The result shows that women who suffer from morning sickness during pregnancy feel a loss of control over their lives which has a significant impact on their mental and physical health making it difficult to function normally. Feelings of isolation, loneliness and alienation are common. It is essential that midwives are attentive in order to provide the help and support that these women require. Conclusion: It is essential that the personnel providing the care are knowledgeable about the condition. More research is necessary to find the root cause of the condition in order to develop effective strategies for treatment.
\end{abstract}

Keywords: Nausea during Pregnancy; Morning Sickness; Experience; Support; Midwife; Qualitative Content Analysis

\section{Introduction}

Nausea, queasiness and vomiting are common symptoms during pregnancy that may at times require hospitalization if deemed serious enough. In order to manage these unpleasant feelings, the pregnant woman needs a good deal of support from the midwife, her environment or from her intimate circle of acquaintances. Typical symptoms are common to morning sickness (emesis gravidarum or EC) and elevated symptoms are related to aggravated morning sickness (hyperemesis gravidarum or HG) (see Table 1).

The onset of morning sickness usually starts around the sixth week of pregnancy and in more than half of the cases it disappears before the twentieth week of pregnancy. Feelings of nausea and queasiness are more common than actual vomiting during early pregnancy [1]. The morning sickness can be divided into mild, moderate or severe morning sickness [2]. Approximately ten percent of pregnant women will experience longer periods of symptoms and in a few cases the condition persists though the entire pregnancy. If the symptoms are left untreated, the condition can have negative influence on organs or cause neurological damage. This extreme case of morning sickness can be fatal to both the woman and the fetus [3].

The exact cause of EC and HG remains unclear, but possible reasons may include high levels of human chorionic gonadotropin (HCG) which is a pregnancy hormone that circulates in the blood. Chronic infection with Helicobacter pylori bacteria which causes stomach ulcers is another probable underlying cause of the morning sickness condition. Psychosocial factors such as stress, poor economy and a lack of social support may also be seen as contributing factors. There is no completely satisfactory treatment for EC and HG and the current treatment is only symptomatic [5].

The onset of morning sickness may at first be a cause of celebration for the couple because it is a typical early symptom of pregnancy. These uncomfortable feelings make it very difficult for women to function normally at work and at home. Women generally try to understand their symptoms within the context of their lives and try to adapt their diet and lifestyles around their symptoms in order to manage their pregnant condition. They may use alternative therapies, stay in well ventilated areas, avoid 
Table 1. Review of the differences between the EC and HG according to Farrell [4].

\begin{tabular}{ll}
\hline Emesis gravidarum (EG) & Hyperemesis gravidarum (HG) \\
\hline Less than 5\% weight loss & Greater than 5\% weight loss \\
Episodes of nausea and vomiting & Constant nausea with frequent vomiting \\
A change in diet or lifestyle is often enough to provide relief. & $\begin{array}{l}\text { Medication possibly together with intravenous fluids } \\
\text { needed to provide relief }\end{array}$ \\
Nausea usually subsides before the twelfth week. & $\begin{array}{l}\text { Nausea continues often until the twentieth week } \\
\text { and sometimes for the duration of the pregnancy. }\end{array}$ \\
$\begin{array}{l}\text { Symptoms can be managed for the woman to maintain her } \\
\text { normal public life. }\end{array}$ & $\begin{array}{l}\text { Symptoms severe enough to cause the woman to be } \\
\text { bedridden and exclude her from public interaction. }\end{array}$ \\
Sporadic disruption of daily public existence. & $\begin{array}{l}\text { Impossible to manage symptoms in public which } \\
\text { may lead to isolation and depression. }\end{array}$ \\
Normal life after pregnancy can resume after one to three months & $\begin{array}{l}\text { Normal life after pregnancy can be delayed from } \\
\text { six months and up to two years. }\end{array}$ \\
\hline
\end{tabular}

strong smells, spend a lot of time sleeping and resting in a semi-sitting position or moving about gingerly [6]. Alternative therapies include acupressure, acupuncture and massage therapy $[2,7]$.

Western culture normally associates feelings of happiness and anticipation with pregnancy. Culture dictates that this is something that a woman should be looking forward to but for women suffering from morning sickness this can be a very stressful experience [8]. Many women who suffer from HG and EC may experience feelings of guilt regarding their condition and studies show that it is common for these women to avoid talking about their condition and seeking professional help [9, 10]. Morning sickness symptoms can make pregnant women so miserable that they may experience feelings of wanting to terminate their pregnancy whether by miscarriage or abortion even though they want to be pregnant.

The women can be so occupied with the misery associated with her symptoms that she feels badly about not managing her relationship with her husband or others in her intimate circle. She is only preoccupied with strategies of how to endure her symptoms. A feeling of helplessness often accompanies the symptoms of EC and HG [10]. Ågren and Berg [7] describe in their study that the women felt as if their lives were going forwards but all of their power and energy was gone. According to $[2,10]$ the women are progressively pulled from their daily routines and social activities because they are actually afraid that they may vomit in public. This increased sense of isolation leads to feelings of loneliness and alienation. It is a long fall from being a strong and healthy woman, who nurtured and independently took care of her environment, to finding herself in need of full time nursing care to survive.

If the symptoms become so severe from HG that it becomes necessary for a woman to be under constant medical supervision which she may experience feelings of hatred for her unborn child and she also may be unable to accept the possibility of becoming pregnant again [11].

Chou, Chen, Kuo, and Tzeng [8] conclude that support is something that all pregnant women feel very important. Their social circle of intimate contacts is of great importance for their health and wellbeing. The people that matter most in their support network are the husband and the mother. In most cases it turns out that the woman's mother is the most important person. The main thing that a supporter of the woman should be aware of is that the suffering woman needs understanding. According to O'Brien [2] virtually the only positive aspect of the morning sickness condition was that the women saw their husbands in a new perspective which could result in the couple becoming closer and tighter. Chou et al. [6] concluded in his study that the more social support a woman has surrounding her, the less she will be influenced by her stress and it also encourages the bonding between the mother and the unborn child in her womb.

Even though most of the women want to avoid hospitalization, when it happens they are satisfied with the treatment and medical care they get that relieves them of their morning sickness symptoms. It's important that the women receive a diagnosis of their condition in order that they feel their condition is recognized and this comes as a relief as well [7,9]. Midwives and the related health care professionals need to have an understanding and knowledge of morning sickness to become aware of the effects the illness has on the woman during pregnancy. It is important that the initial response from the midwife is positive to the woman. The suffering women have a difficult time accepting from the midwife that their illness is of a psychosomatic nature [11]. Chou [8] describes that it is important to identify the risk factors associated with the morning sickness in order to prevent or minimize the symptoms and to enable a more holistic care of pregnant women.

Wills and Forster [12] conclude in their study that the advice that midwives most commonly provide is changes 
regarding diet and lifestyle. Although alternative treatments such as acupuncture and acupressure were found to be effective at times, the midwives advised combining some of the various options available in order to achieve some relief from the symptoms. Ågren and Berg [7] documented women's experience of light touching massage that gave them a momentary respite from the nausea that had otherwise taken complete control of their lives. The touching massage gave the women a feeling of solace and enabled the women to believe that they could endure and survive their condition and suffering. Even though the treatment may only give a very temporary respite, they could feel a bit rejuvenated with their energy and may even experience a return of appetite which gave them a chance to eat.

The International Code of Ethics for Midwives (ICM) [13] declares that midwives should respect each individual woman's choice in all possible situations and outcomes, while supporting their decisions that they make regarding their condition. This support consists of encouraging the women to speak up for themselves regarding their health and that of their families. The midwives must also endeavor to sympathize with the women within their own individual cultural and social parameters. The duty of the midwife is to enable the women to maintain their self-respect and sense of integrity through their period of suffering. If they are failing in this regard then they should seek the support of others in the health care services.

The aim of the study was to describe the women's experience of their morning sickness and the support of their condition after they had given birth to their child.

\section{Method}

\subsection{Participation and Procedures}

The method chosen to conduct this study was to create and deliver a questionnaire and a letter providing information about the study to the twelve participating women. The questionnaire method was chosen as it gave the participants a convenient and confidential venue to express and expound upon their intimate feelings regarding their suffering [14]. The questionnaire was structured around some basic questions regarding four aspects of their experience and augmented with some open questions which gave them a chance to elaborate [15]. The questions were designed to paint a picture of each woman's experience of their morning sickness and the support that they received from the midwives. The questions were also designed to get input from the women on how to improve understanding of their condition and how to improve the care of morning sickness.

The selection of the participants was accomplished by a number of different means. There were five women that had participated in a support group for their morning sickness during their pregnancy and they were invited by letter when the operations manager received permission to conduct this study. Another woman was invited that had attended an antenatal clinic where she was being treated by a midwife after her pregnancy. Two more participants saw a letter of information about the study in the same antenatal clinic and they asked to participate. Four more women heard by word of mouth about the study and they requested to participate. This made a total of twelve participants. The only inclusion criteria for participation were that the woman had experienced some level of morning sickness, either EC or HG, and no distinction was made regarding the severity. The exclusion criteria were that the participants must be able to speak Swedish and that they were not pregnant at the time the questionnaire was being answered [16].

Participants were given one week to respond to the questionnaire. By the time the response time had expired there were only four questionnaires that had been completed and a decision was made to send out a reminder letter to the participants who had not responded. Five participants responded to the reminder which gave a total response rate of 75 percent (See Table 2).

\subsection{Data Analysis}

Qualitative content analysis was used to analyze the collected data with an emphasis on examining and interpreting the answered questionnaires. Four basic questions about different aspects of their experience were asked in the questionnaire and each of these constituted a domain. The authors read the answers through several times to get a deeper understanding of the whole. The data was condensed and further shortened into meaning bearing units in order to gain a better understanding and to obtain a clearer picture of the contents. The meaning bearing units were even further condensed and assigned a code. Several codes make up a subcategory and several subcategories make up a category. Differences and similarities were combined and expressed in six categories and two themes that made up the context of the study [15]. A summary of the analysis process has been completed (see Table 3).

The answers to the questionnaire were divided into two themes. The first theme was "Being a slave to the body" and the second became one of "Life support measures" (see Table 4).

The collection of empirical data was taken using the Declaration of Helsinki and the Medical Research Council as a guideline. The questionnaire was designed to achieve the objectives of the master thesis and it takes into account all relevant ethical considerations such as information, consent, confidentiality and use of requirements [17]. This defines that participants shall be informed 
Table 2. Summary of background information of participants.

\begin{tabular}{|c|c|c|c|c|c|}
\hline No. & Age & \# of births & Time elapsed since pregnancy & Marital status & Level of education \\
\hline 1 & 30 - 39 yrs. & multiple & 40 weeks & living together & High School \\
\hline 2 & 30 - 39 yrs. & Multiple & 15 weeks & living together & Some college \\
\hline 4 & 20 - 29 yrs. & First & 16 weeks & living together & High School \\
\hline 6 & 30 - 39 yrs. & Multiple & 40 weeks & living together & High School \\
\hline 7 & $20-29$ yrs. & First & 12 weeks & living together & High School \\
\hline 9 & 30 - 39 yrs. & First & 27 weeks & living together & Some college \\
\hline 10 & 30 - 39 yrs. & Multiple & 40 weeks & living together & High School \\
\hline 11 & 20 - 29 yrs. & Multiple & 16 weeks & living together & Some college \\
\hline 12 & $30-39$ yrs. & First & 40 weeks & living together & High School \\
\hline
\end{tabular}

Table 3. Description of the analysis process: meaning bearing units, condensed meaning bearing units code, sub-category and category.

\begin{tabular}{|c|c|c|c|c|}
\hline Meaning bearing unit & $\begin{array}{l}\text { Condensed meaning } \\
\text { bearing unit }\end{array}$ & Code & Sub-categories & Categories \\
\hline $\begin{array}{l}\text { My partner saw my discomfort } \\
\text { and confirmed my suffering }\end{array}$ & $\begin{array}{l}\text { My partner saw me and } \\
\text { confirmed me }\end{array}$ & Be confirmed by the partner & \multirow[t]{2}{*}{ Importance of confirmation } & \multirow{5}{*}{ The strength to persevere. } \\
\hline $\begin{array}{l}\text { Luckily we live with my family } \\
\text { so daily chores were not an issue }\end{array}$ & Family was there for me & The family gave support & & \\
\hline My partner was a good supporter & & & \multirow{3}{*}{ Support gave strength } & \\
\hline $\begin{array}{l}\text { He massaged me...relaxing my } \\
\text { whole body and gave a respite } \\
\text { from the illness } \\
\text { He gave me energy }\end{array}$ & $\begin{array}{l}\text { My partner gave me energy } \\
\text { and power through massage } \\
\text { and support. }\end{array}$ & $\begin{array}{l}\text { My partner's support gave } \\
\text { me strength }\end{array}$ & & \\
\hline $\begin{array}{l}\text { Someone who listened without } \\
\text { giving advice }\end{array}$ & $\begin{array}{l}\text { Someone who listened } \\
\text { closely }\end{array}$ & $\begin{array}{l}\text { Ability to talk about the } \\
\text { condition }\end{array}$ & & \\
\hline
\end{tabular}

Table 4. Expression of results: divided into four domains, sixteen sub-categories, six categories and two themes.

\begin{tabular}{lll}
\hline Domains & Sub-Categories & Categories \\
\hline Experience & Difficulties enduring Loss for zest of life & Importance \\
& $\begin{array}{l}\text { Panic emotions and feelings Not knowing } \\
\text { if you can hold out Being vulnerable and alone }\end{array}$ & Fear \\
Strategy & $\begin{array}{l}\text { Accepting the tough reality Take things one } \\
\text { day at a time Bite the bullet and don't show it }\end{array}$ & Tactics \\
Support & Being dependent on significant others In need of help & Perseverance \\
& Feel pampered Feeling left out There’s nothing to do & Involvement \\
Development & $\begin{array}{l}\text { Yearning for health Wishing for answers Need for } \\
\text { explanation and understanding }\end{array}$ & Weakness \\
\hline
\end{tabular}

about their role in the project and about the conditions for their participation. Participants are to be informed that their participation is voluntary and they have the right at any time to withdraw from the study. Participants are to be given the opportunity to decide whether for how long and under what conditions that they will participate. Consideration of ethical issues was conveyed in the in- formation letter which was designed in accordance with the Ethical Review Board guidelines. The participants gave their consent for the study by filling in the questionnaire after the information letter was read. Consent is considered to be granted under the Review Board guidelines when a questionnaire is filled in and returned with the understanding that the participants have read the 
information letter through

\section{Results}

The results are reported under the two themes, "To be a slave to the body" and "Life support measures" that emerged during the analysis made of the participants' written responses to the questionnaire (Table 4).

\subsection{To Be a Slave to the Body}

The women discuss the experience of EC and HG as being something unspeakable and despicable that drove them to the point of panic. Several of them have clearly stated that this experience was worst thing that had ever happened to them in their whole life and they could only describe it as traumatizing. People generally think that morning sickness is something that is a natural part of the pregnancy experience and the participants felt that this was a terrible way to approach the issue. In a normal and relatively uncomplicated pregnancy there is certainly an element of fatigue and of being tired, but when you are experiencing constant nausea the combination of the two factors can make the experience unbearable. The sensation that their bodies had stopped working from protecting them from the nonstop nauseous feelings and the sensation that all of the power and energy had been sucked out of them was a physically, emotionally and spiritually intimidating experience for the women.

Visual and olfactory impressions could often trigger the nausea. Even emotional feelings could be a catalyst for the sickening feelings. Without any escape from the nausea the women felt powerless, empty and apathetic. The participants describe that at times they could not even stand up or walk. Naturally they were totally depleted of almost all living sensations if they were constantly nauseous and vomiting several times a day. This left them basically bedridden. The patients found themselves trying to lie very still and on their sides in order to abate the nausea. When they were able to sleep they were able to escape from their miserable condition.

Morning sickness of levels either EC or HG are described as extremely stressful and despite plenty of rest and being practically bedridden the significance of the alarm clock was an important factor. If not for that, the immense fatigue that dominated their lives around the clock made some participants describe that they could have slept around the clock otherwise. The overwhelming symptoms made it difficult to focus on life itself. Even totally passive activity such as watching television was demanding. Women expressed feeling joyous when they experienced even low amount of energy or power. The women described trying to summon the energy to listen to an audio book or to simply take a shower. Even so the feeling of weakness may be so overwhelming that the women would have to shower sitting down.

One woman told how she would become sick to the point of vomiting when she brushed her teeth and when she didn't brush she felt nauseous anyways. They even had difficulty swallowing their own saliva and used spittoons to spit it away.

"Pure hell..."

"I wouldn't wish this on my worst enemy!"

The condition was really tough on the women both physically and mentally. They felt to the point of being mentally ill when the nausea came over them. Participants found it really difficult to rejoice over the child in the womb while they experienced EC or HG. The misery drove some of the women to thoughts of ending their pregnancy whether it would be by miscarriage or abortion and this in turn gave them further feelings of angst. They would vow to themselves to never subject themselves to these feelings again. They vowed to never become pregnant again. At their worst the women felt that they wanted to die. Their life consisted of days of being bedridden and attempting to eat and drink.

"I ate, slept and cried..."

Several of the women were bedridden most of the days when they were experiencing morning sickness and they could have trouble sleeping at night as well. As a result they experienced a lot of difficulty when trying to cope with work. The debilitating factors of nausea and fatigue left them feeling that it was impossible to perform their work tasks competently. Additionally participants described episodes of vomiting in their car on the way to work while they continued to vomit throughout their working day. It was normal that the women would be given a written permission from their doctor to be away from work during their morning sickness but when they were to return it was often difficult because the symptoms were still persisting. Even if the women were able to do their work they felt that their performance had definitely been compromised and they were not up to their normal level at all. One woman expressed thankfulness when she was unemployed because she felt that managing a job was out of the question in her condition.

The symptoms of their medical condition made it difficult for the whole family. Children were afraid and upset because they didn't recognize their mothers through her suffering. Children avoided being in their mothers presence. Women who normally spent all of their available time mothering their children prior to their symptoms were unable to do so except on a very limited basis. These women were actually terrified of vomiting in public which made it virtually impossible to go out into the world and to function normally.

"My bucket is my constant companion..."

The women found the condition more and more difficult to tolerate after they had been given assurances that 
at certain intervals of the pregnancy their symptoms would go away. When the conditions persisted it could lead to depression. The idea that the symptoms could persist for the entire duration of the pregnancy could give the women a reason to panic. The persistent feelings of nausea and the vomiting actually caused the women to withdraw into themselves and left them feeling isolated. This was an overwhelming feeling for the women. Two of the participants of the study were found to have repressed a good deal of the experience but they realized that others were enjoying the pregnancy experience. Other women commiserated that nobody could possibly understand how it felt to have morning sickness. The participants often found themselves in awe of their own selves and how they were able to endure the situation and conditions. Slowly they found themselves trying to accept the situation for what it was.

"In the end...it was just to bite the bullet."

Their bodies were on the edge the whole time trying to defend itself from the torment of nauseous feelings and it was very difficult to find successful strategies to relax. The prevailing attitude about morning sickness was that it shouldn't affect the mental or physical wellbeing of a woman. The women thought that family history or prior experiences should not be an influence upon their condition. They could not accept the idea that morning sickness could in some way be psychosomatic.

The participants in the study expressed disapproval of the attitude that there is a psychological root cause of morning sickness of some midwives. This was interpreted as a bad attitude by the midwife. Another woman thought that fatigue may be the cause of her sickness. Participants were open to the possibility that the symptoms could somehow be linked to factors such as in vitrofertilization, low estrogen production, sensitivity to pregnancy hormones or metabolism. One participant thought that her condition may be connected to hyperthyroidism for which she was diagnosed with during her pregnancy. Liver functions and sensitivity were suspected by the women to have an influence on their symptoms. The ideas that somehow the way that the child was positioned in the womb or the sex of the child could have something to do with the morning sickness condition were other topics of discussion. There is a myth that nausea can become worse if the fetus is of the female gender and this was discussed by the participants.

\subsection{Life Support Measures}

Participants described multiple strategies to manage their condition. Many described having tried everything to cope with the condition but there was nothing that gave them complete relief. During pregnancy when their condition was at its worst, the focus of coping was a minute by minute, hour by hour, day by day and week by week ordeal. To hold out became the goal during pregnancy. The need to take a minute or some hours at a time became a dominant theme to shield them from the outside world. The women tried to maintain a positive attitude towards their condition but this rarely had any effect. Most of the participants tried medication for nausea but usually it was without experiencing any significant or lasting improvement. The women also described uneasiness about taking excessive medication during pregnancy.

The feeling of not wanting to eat was very strong because eating often resulted in vomiting. But not eating was counterproductive too. The women tried to find effective procedures where they could eat without vomiting. Food such as crisp bread, rosehip soup, yogurt and fruit were foods that women could generally bring themselves to eat. Strategies for managing EC and HG were to avoid cooking and staying away from environments with cooking smells. Eating small portions frequently was another strategy for managing nausea and vomiting. One participant went to bed immediately after eating so as not to vomit. Others used the time immediately after vomiting to try and ease some food and nourishment into their systems.

Getting the necessary support from their partners and their environment was needed in large quantities. Without this support it was impossible to cope with the situation according to participants. It was important for the women to have confirmation of their morning sickness. Many significant others in the women's circle had advice as to how to counteract the nausea. This could become a source of irritation to the women when they felt that they were trying everything without success. Another source of irritation was when they were told that their condition would improve over time and it did not. It was more important to have someone to listen to them than to have someone giving them advice. Some of the women felt that the best overall support came from their partners. The participants' partners also had different strategies to provide support and relief. It was found that perhaps the best support was in touching as with scalp and tactile massage. This was found to help them to relax.

"The touching and contact gave me the sensation that I was getting a break from my own body..."

Getting help with household chores and food preparation was perceived as supportive and helpful. It was very supportive to have other family members such as parents lending their assistance to the situation. The women were grateful if there were neighbors or others in their immediate vicinity that provided sympathy. Obviously this could be very trying on the partner and the women were really thankful when they were forgiven for their terrible moods when they were ill. Most of the women felt that they got the necessary help and support in order to manage 
their ordeal.

When it came to the professional support from the midwife the women expressed how important it was that the midwife appeared to be anxious to help them. The midwives were perceived as supportive and they confirmed to the women how intense the loneliness could be as a result of their condition. The midwives gave their support by listening and expressing their confirmation, by giving advice and discussing their condition and extending an invitation to a support group. The advice women received from the midwife was primarily regarding their diet and the change in lifestyle. They were advised to get plenty of rest and to eat small meals regularly. Midwives prescribed acupressure band, acupuncture and reflexology as plausible treatment for morning sickness. Medication for nausea and motion sickness were also recommended by the midwives. There were women who felt that they did not receive adequate support. These women may end up admitting to themselves that they themselves may have contributed to their own ineffective support because they had the idea that no one else could possibly understand how badly they felt. Sometimes the women were confronted with the attitude or opinion that there wasn't much to do with regard to their morning sickness. One participant did not think she was getting adequate support from her midwife because her only remedy was to get her an appointment with the doctor.

"The midwife told me that there wasn't much that could be done to help me..."

Even though most of the women were satisfied with the assistance and support they received from the midwife they were still very unhappy that there was nothing that could relieve the morning sickness. Most of the women who had been hospitalized were very satisfied with the support they received from the staff. They felt that the midwife had compassion for their situation and their condition. The knowledgeable staff and the safe confines of the hospital gave the women a sense of security but once they were discharged they could feel the return of the panicky emotions when their symptoms returned. Sometimes the women were reluctant to fully trust in someone who had not experienced their condition and they lacked confidence in them to treat them.

In conclusion the women felt that they needed more written and oral information about their condition and about the prospect of it enduring their entire pregnancy. Very few people can really understand the plight and discomfort of a woman who is plagued by extreme cases of morning sickness. The midwife demonstrates that she is in touch with the women by closely listening to their experience which confirms her support to the women. It was very important for the suffering women to be treated compassionately and taken seriously and it was important that there was professional help available to offer advice on what could alleviate their suffering. One case in a gynecology clinic was viewed as being treated inadequately by a nurse with insufficient knowledge of the morning sickness condition. The experience was described as horrible and gave the patient feeling of vulnerability and loneliness because she was not given the necessary support that the condition required. Other cases that were treated in the antenatal unit experienced a big difference in the level of caring as the midwives were perceived as knowledgeable, responsive and very supportive. The hospital staff needs to be knowledgeable in the care of women with morning sickness because these women may need to be hospitalized in the future and if they do not have confidence in the system they may refuse to be hospitalized. After the women were hospitalized they preferred to have the option to be released after conferring with their midwife. Then they could return to the hospital if their symptoms persisted and this gave them a sense of security.

Home visits were suggested by some by some women as a viable option to improve the care of women who are suffering from EC and HG. This would be an option for women that were feeling so bad that they could not endure a trip to the antenatal clinic. It was important that the partner of the women should be actively involved and given adequate advice and education with regard to the morning sickness condition in order for them to be more effective in giving their support. Touching treatment in the form of massage was found to be effective in treatment for morning sickness and was recommended by the midwives. Therapy groups including women that are similarly afflicted gave the women a chance to discuss their symptoms and should not be dismissed as too complicated to administrate. The women in the study proposed that they be given more frequent appointments with the midwife when they suffered from EC and HG. The women in the study wanted to know the reason why they had this elevated morning sickness and wanted medication to alleviate their symptoms. Generally speaking, the care among the women was considered to be functionally passable but they felt that there was some room for improvement in the treatment of women with morning sickness.

\section{Discussion}

Even though this study has treated both EC and HG under the one heading of morning sickness there is a definite distinction between the two conditions. Within the context of our study this distinction was not considered to be of value. It is important to know that the difference exists as reported initially in the background information (see Table 1). One significant difference in our study from previous research is that all of the women who par- 
ticipated were not pregnant at the time of our research. The experience of having morning sickness was a traumatic experience for the women and the need for support is clearly evident based on our findings and those of previous studies. This support is both social and professional in nature.

One very interesting aspect of morning sickness is that the reason for it is not known. Several of the women expressed a desire to know just what it was and why it was making them so ill. Women in the study believed that their illness could be due to hormonal changes in their bodies, in their liver functions, due to in vitro fertilization, metabolism or even due to the gender of the baby or the position that it was laying within the womb. A majority of the women were certain that the condition was not a purely psychological one.

In our study there was one woman who independently sought information on the internet for advice about strategies that could help in managing the sickness but she was unable to come up with any clearly definitive working alternatives. According to Hirschberg [5], there is no current satisfactory cure and the treatment must be symptomatic. Milder cases of morning sickness at the EG level were found to be manageable with lifestyle and dietary changes, but in more severe cases medical treatment and sick leave were necessary. Chan [1] opined that psychosocial support should be provided by the health care system and this could be managed by telephone contact as well as through internet forums. According to Chou et al. [8] it is vitally important that treatment for the morning sickness condition must be initiated in a timely and orderly manner to reduce and minimize the symptoms. A majority of the women opted for more homeopathic treatments such as diet modification or acupressure and acupuncture as opposed to using medicinal treatment [11].

Many times the women in the study expressed that their morning sickness left them with a feeling of loneliness, as if they were suffering alone, which then led them to a feeling of being isolated because the condition led them to keep it to themselves. Feelings of panic, anxiety and helplessness often accompany the feelings of loneliness and isolation. These feelings could give way to negative thoughts and impulses that led them to the questions about abortion or miscarriage which in turn could result in more anxiety and guilt. These feelings and thoughts were confirmed in the study [10].

The women of the study found that the most important thing was to get confirmation of their illness from their support group and that the support group should more importantly listen closely rather than offer advice. According to Berg, Lundgren, Hermansson and Wahlberg [18], it is important that the personnel who are giving the professional support should have knowledge that is evi- dence based. The professional support is most importantly experienced, and they should have a lot of experience in managing women who are similarly afflicted. Every time they meet with a new patient it is a unique experience so they professionally acquire a little more understanding and are therefore further enabled to be more compassionate on a patient by patient basis.

It is clear that as a result of our study that the care of women that are suffering from morning sickness should be reviewed. Munch [9] confirms that it is important that health care providers should have specialized knowledge of the EC and HG conditions in order to provide more engaged care for the patients. According to the Chou et al. [6] findings, it is very important that women get the proper support from their environment and the healthcare system in order to deal with the strain on their lives that the morning sickness creates. Chatting with the midwife can be a very effective method of professional support [19]. It is important that the midwife recognizes that there are different individual ways that women think their way through their pregnancy which is what essentially enables them to support each woman on an individual basis [18].

In this study it was apparent that all of the women were pretty satisfied with the support that they were receiving in their predicament. But we are aware that this study is unique in that it took place in Sweden and there are many other different conditions worldwide which would have further implications. It may be interesting to conduct a similar study with a wider range of participants in terms of demographics to see if the results hold on to their meaning.

All of these women in the study agreed that the suffering that they experienced from their morning sickness was the worst trauma that they had ever experienced. It is important that the persons that are providing environmental and professional support to women with morning sickness should be attentive listeners. They should always confirm the women's feelings and suffering and give them compassionate individualized care. These common concerns of the women indicate that clearly there must be an improvement in the healthcare system surrounding women that are afflicted with morning sickness. Hopefully, through further research clarification may be obtained about the specific causes of morning sickness and successful strategies can be developed and implemented that can help these women to lead a normal life during their pregnancy.

Information about the morning sickness condition is currently considered to be lacking or even flawed and this makes it difficult to fully understand the full scope and implications of the condition. It is a common misconception that women that are pregnant are in some sort of blissful state and it is very important to understand 
that this is simply not the case. The internet is an important tool in society today and it should be used effectively to provide information and support for women who are suffering from morning sickness. Midwives should establish, design and maintain websites to insure that information that is circulated about this condition is accurate, informative and helpful. Perhaps the support that was most appreciated by the women in the study came from their partner and with this in mind it is important that the partner also be provided with the necessary support in order that they can provide the best support possible. Internet forums are also needed for the partners of women who are suffering from morning sickness, as they need a place to exchange tips and advice as well.

Exactly where the care should take place is not always specific. It is possible that women should have the option of a home visit if they are unable to make it to the antenatal clinic or hospital on their own. Very importantly it must be emphasized that more research is clearly needed, especially in Sweden, to establish what the causes of morning sickness are. This would of course give better treatment strategies which will promote pregnancies that are easier to manage and therefore not make life so miserable for women that are pregnant that suffer from morning sickness.

\section{Acknowledgements}

The authors' thanks the women who shared their experience from a hard time in their life.

\section{REFERENCES}

[1] O. K. Chan, D. S. Sahota, T. Y. Leung, L. W. Chan, T. Y. Fung and T. K. Lau, "Nausea a Vomiting in Health-Related Quality of Life among Chinese Pregnant Women,” Australian and New Zealand Journal of Obstetrics and Gynaecology, Vol. 50, No. 6, 2010, pp. 512-518. doi:10.1111/j.1479-828X.2010.01216.X

[2] B. O’Brien and S. Naber, "Nausea and Vomiting during Pregnancy: Effect on the Quality of Women's Lives," Birth, Vol. 19, No. 3, 1992, pp. 138-143. doi:10.1111/j.1523-536X.1992.tb00671.x

[3] C. McParlin, R. H. Graham and S. C. Robson, "Caring for Women with Nausea and Vomiting in Pregnancy: A New Approach,” British Journal of Midwifery, Vol. 16, No. 5, 2008, pp. 280-285.

[4] N. Farrell, "Hyperemesis Gravidarum: How Midwives Can Help,” The Practising Midwife, Vol. 11, No. 7, 2008, pp. $12-14$.

[5] L. A. Hirschberg, In: H. Hagberg, K. Marsál and M. Westgren, Eds., Obstetrik (uppl. 1:2), Studentlitteratur, Lund, 2008, pp. 427-432.

[6] F. H. Chou, K. C. Avant, S.-H. Kuo and S. J. Fetzer,
"Relationships between Nausea and Vomiting, Perceived Stress, Social Support, Pregnancy Planning, and Psychosocial Adaption in Sample of Mothers: A Questionnaire Survey," International Journal of Nursing Studies, Vol. 45, No. 8, 2008, pp. 1185-1191. doi:10.1016/j.ijnurstu.2007.08.004

[7] A. Ågren and M. Berg, "Tactile Massage and Severe Nausea and Vomiting during Pregnancy-Women's Experiences," Scandinavian Journal of Caring Sciences, Vol. 20, No. 2, 2006, pp. 169-176. doi:10.1111/j.1471-6712.2006.00394.X

[8] F. H. Chou, C. H. Chen, S. H. Kuo and Y. L. Tzeng, "Experience of Taiwanese Women Living with Nausea and Vomiting during Pregnancy," Journal of Midwifery \& Women's Health, Vol. 51, No. 5, 2006, pp. 370-375. doi:10.1016/j.jmwh.2006.04.009

[9] S. Munch, "A Qualitative Analysis of Physician Humanism: Women's Experiences with Hyperemisis Gravidarum,” Journal of Perinatology, Vol. 20, No. 8, 2000, pp. 540-547. doi:10.1038/sj.jp.7200464

[10] B. O’Brien, M. Evans and E. White-McDonald, "Isolation from 'Being Alive': Coping with Severe Nausea and Vomiting of Pregnancy,” Nursing Research, Vol. 51, No. 5, 2002, pp. 302-308.

[11] L. Locock, J. Alexander and L. Rozmovits, "Women's Response to Nausea and Vomiting in Pregnancy," Midwifery, Vol. 24, No. 2, 2008, pp. 143-152. doi:10.1016/j.midw.2006.12.001

[12] G. Wills and D. Forster, "Nausea and Vomiting in Pregnancy: What Advice Do Midwives Give?” Midwifery, Vol. 24, No. 4, 2008, pp. 390-398. doi:10.1016/j.midw.2007.05.002

[13] International Confederation of Midwives, "Global Standards for Midwifery Regulation,” 2011.

http://www.internationalmidwives.org/assets/uploads/doc uments/Global\%20Standards\%20Comptencies\%20Tools/ English/GLOBAL\%20STANDARDS\%20FOR\%20MID WIFERY\%20REGULATION\%20ENG.pdf

[14] S. Kvale, "Den kvalitativa forskningsintervjun (uppl. 1: 16),” Narayana Press, Odder, 2007.

[15] B. Lundman and U. H. Graneheim, "Quantitative Content Analyses,” In: M. Granskär and B. Höglund-Nielsen, Eds., Applied Qualitative Research in Health Care, Studentlitteratur AB, Lund, 2008, pp. 159-172.

[16] D. F. Polit and C. T. Beck, "Essentials of Nursing Research-Methods, Appraisal, and Utilization,” 6th Edition, Lippincott Williams \& Wilkins, Philadelphia, 2006.

[17] "The ICN Code of Ethics for Nurses," International Council of Nurses, 2012.

http://www.icn.ch/about-icn/code-of-ethics-for-nurses/

[18] M. Berg, I. Lundgren, E. Hermansson and V. Wahlberg, "Women's Experience of the Encounter with the Midwife during Childbirth,” Midwifery, Vol. 12, No. 1, 1996, pp. 11-15. doi:10.1016/S0266-6138(96)90033-9

[19] M. Berg and I. Lundgren, "To Support and Strength, Caring at Birthgiving,” 3rd Edition, Studentlitteratur AB, Lund, 2010. 